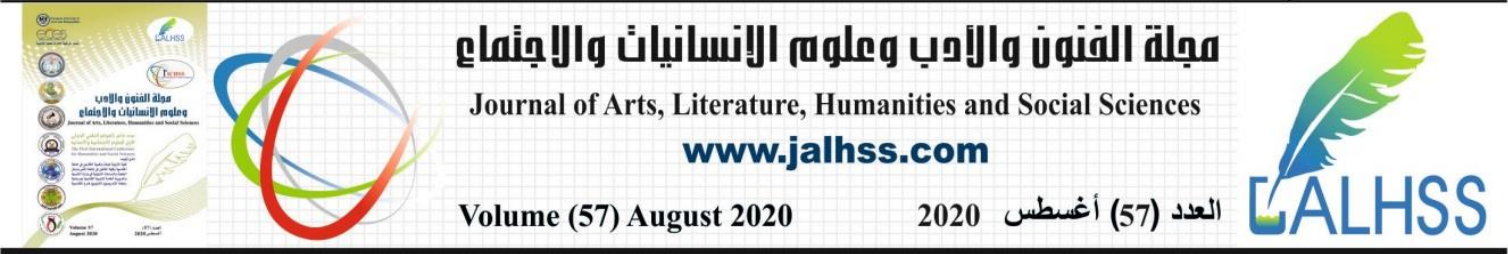

\title{
اثر جائحة كورونا على مدد الطعن بالأحكام القضائية
}

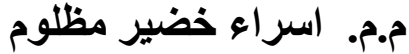 \\ كلية القانون - جامعة كربلاء ـ العراق مقاق مقائ \\ israaalshamaery@gmail.com الايميل
}

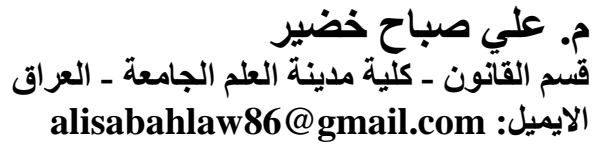

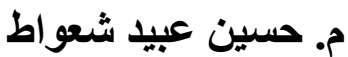

كلية القانون - جامعة القادينة ـ العراق

Hussein.ali@qu.edu :الايميل

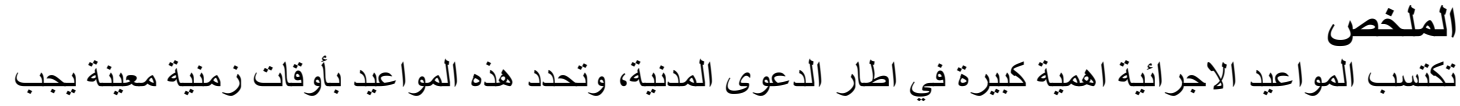

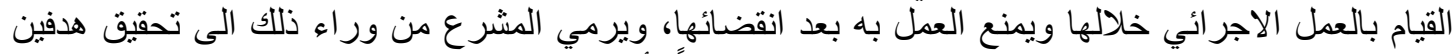

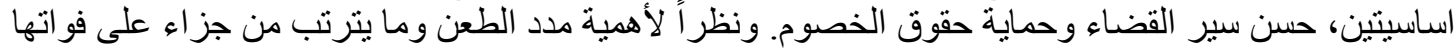

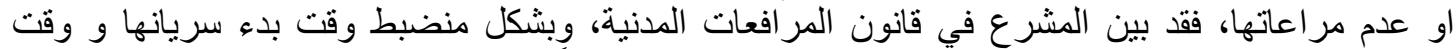

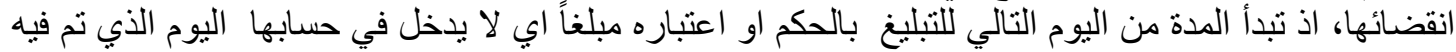

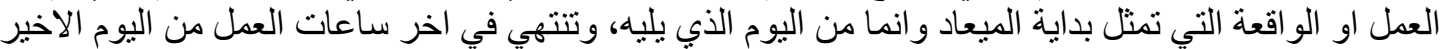

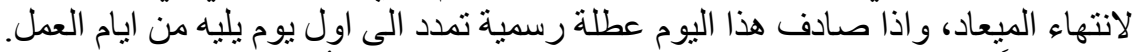

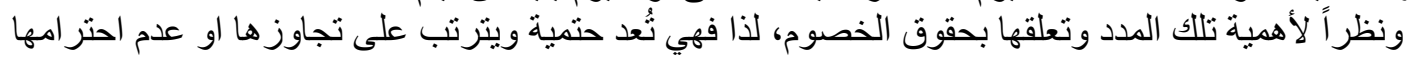

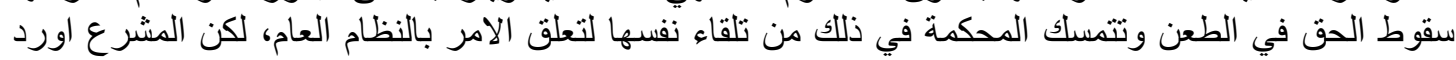

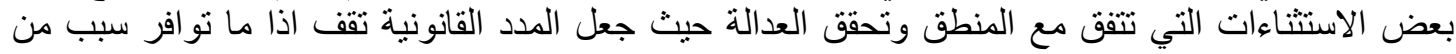

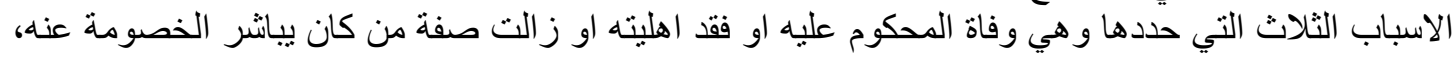

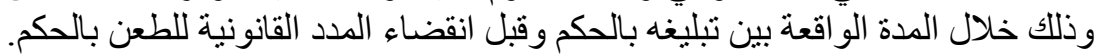

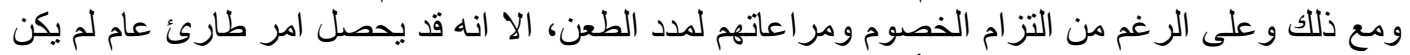

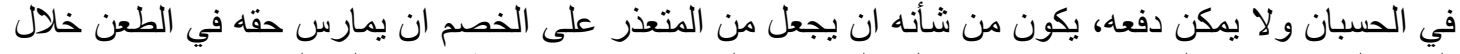

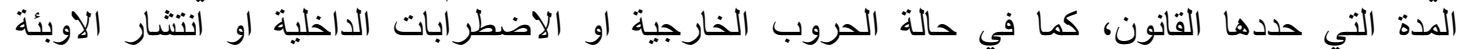

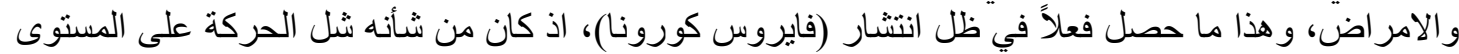

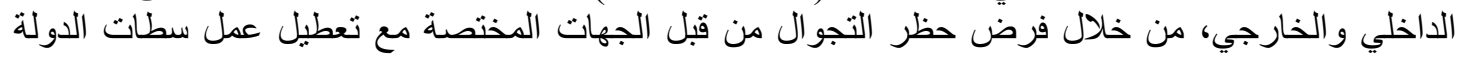

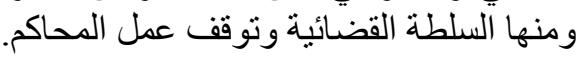

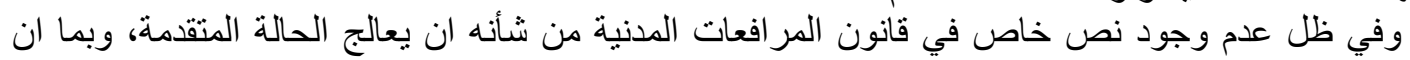

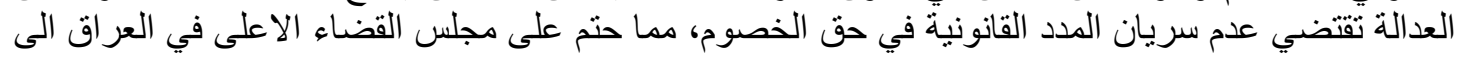

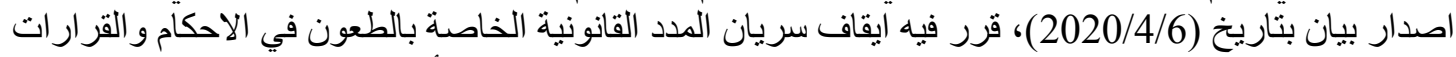

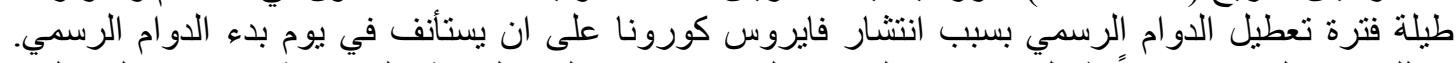

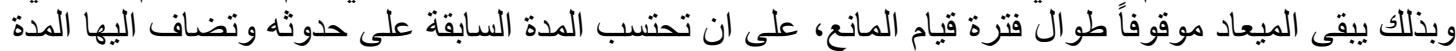
اللاحقة بعد زواله من اجل استكمال المدة التي يتطلبها القانعا عالنون. 


\title{
$00=-$ \\ The Impact of the Corona Pandemic on the Terms of Appeal against Judicial Rulings
}

\author{
Assist. Lect. Israa Khudair Madhloum \\ College of Law - University of Karbala - Iraq \\ Email: israaalshamaery@gmail.com \\ Lect. Ali Sabah Khudair \\ Department of Law - University College of Science - Iraq \\ Email: alisabahlaw86@gmail.com \\ Lect. Hussein Obaid Shwat \\ College of Law - University of Qadisiyah - Iraq \\ Email: Hussein.ali@qu.edu
}

\begin{abstract}
Procedural dates acquire great importance within the framework of the civil lawsuit, and these dates are determined by certain times of time during which procedural work must be carried out and work is prevented after its expiry, and the legislator aims behind this to achieve two main goals: improving the course of the judiciary and protecting the rights of litigants. In view of the importance of the periods of appeal and the consequent penalty for its failure or non-observance, the legislator has made clear in the Civil Procedure Law, in a disciplined manner at the time of its entry into force and the time of its expiry, as the period starts from the day following the notification of the ruling or is considered an amount, i.e. it does not come into its account on the day that was done There is work or incident that marks the beginning of the date but rather from the day that follows, and ends in the last hours of work from the last day of the end of the date, and if this day falls on an official holiday, it is extended to the first day of the next working days. In view of the importance of those periods and their attachment to the rights of opponents, therefore, they are considered inevitable, and their violation or lack of respect results in the fall of the right to appeal, and the court adheres to this on its own to attach to the matter of public order, but the legislator mentioned some exceptions that are consistent with logic and achieve justice where he made legal periods stand If there is one of the three reasons that he specified, that is, the death of the convict, the loss of his eligibility, or the character of the person who was conducting litigation about him, during the period between the notification of the judgment and before the expiry of the legal periods for appeal against the judgment. Nevertheless, despite the parties' commitment to observe the terms of the appeal, a general emergency order may arise that was not taken into account and cannot be paid, which would make it impossible for the opponent to exercise his right to appeal during the period specified by the law, as in the case of wars External, internal disturbances, or the spread of epidemics and diseases, and this is what actually happened in light of the spread of (Corona virus), as it would have paralyzed movement at the internal and external levels, by imposing a curfew by the competent authorities while disrupting the work of state authorities, including the judiciary, and stopping The work of the courts.
\end{abstract}

Keywords: period of appeal, judicial rulings, period of failure, period of limitation, inevitable periods of appeal. 


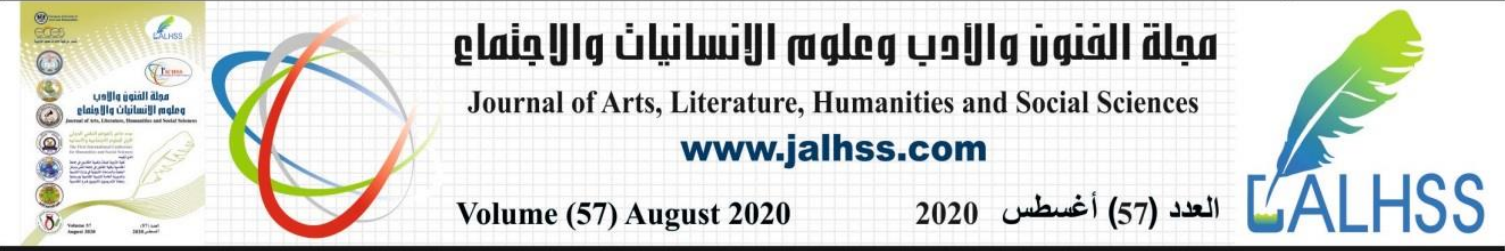

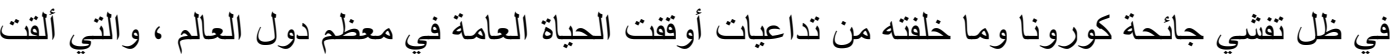

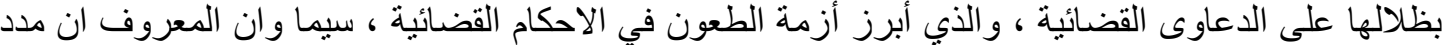

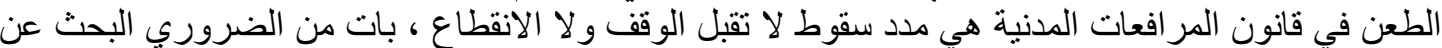

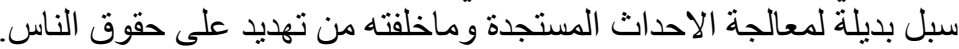

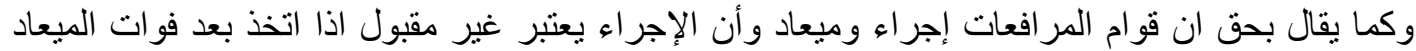

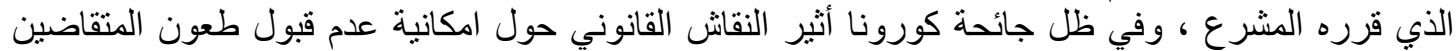

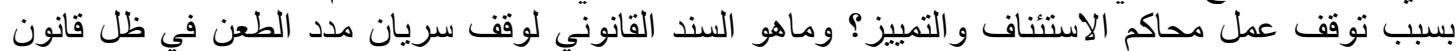

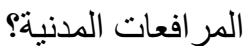

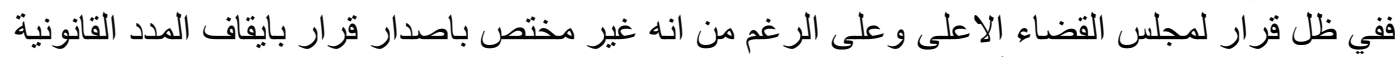

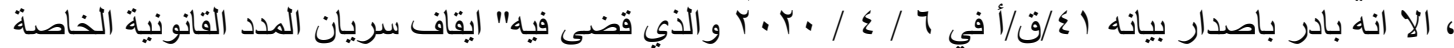

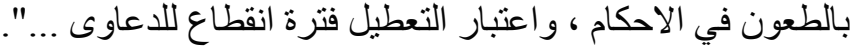

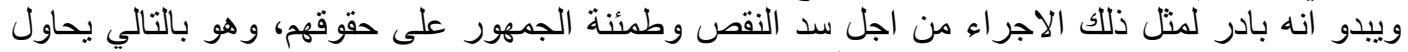

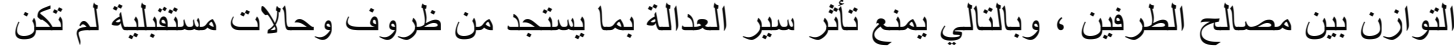
بالحسبان توقعها و هو مايدور حوله موضو عالت بحثنا هذا الا و هو جائحة كورونا.

في ضوء ما ذكر سنقسم هذا البحث على مطلبين ، نبين في المطلب الاول ماهية مدد الطعن في الاحكام ،

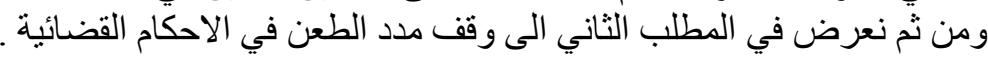

\section{المطلب الاول

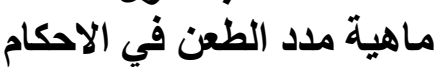

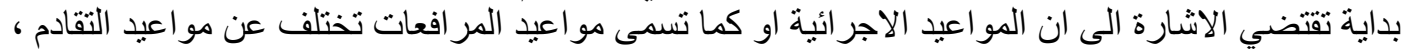

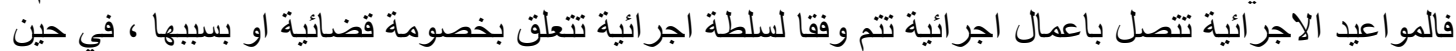

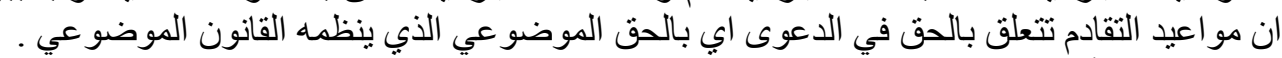

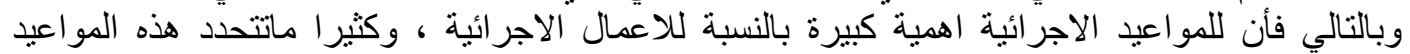

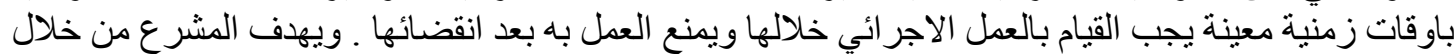

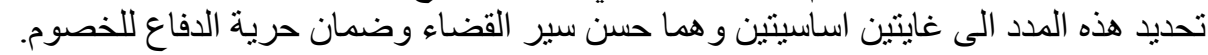
وقد نص المشرع العر اقي في المادة 168 من قانون المر افعات المدنية المنية العر اقي رقم 83 لسنة 1969 على

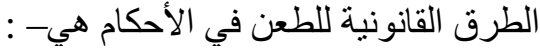
1ـ الاعتر اض على الحكم الغيابي ـ الاستئناف. اعادة المحاكمة. التمييز -تصحيح القرار التمبيزي ـ اعتر اض وبغية بيان ماهية هذه المدد يقتضي منا بيان تعريفها ومن ثم بيان بدء سريانها ، و واخير ا بيان ميعاد انتهاءها

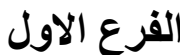 \\ تعريف مدد الطعن}

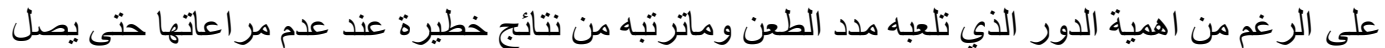

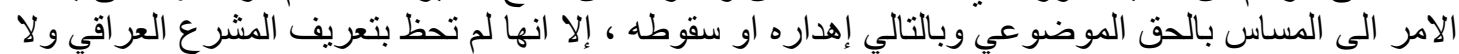

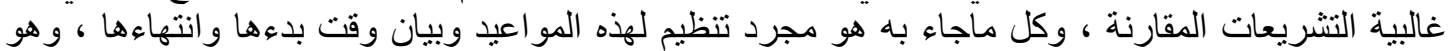
مابينته المواد (25) من قانون المرافية افعات المدنية العرافية اقي رقم 83 لسنة 1969 1969 القابلها المادة 15 من قانون

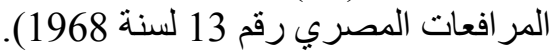

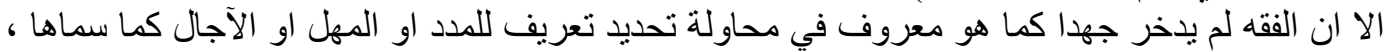

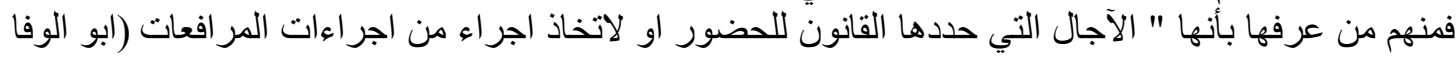




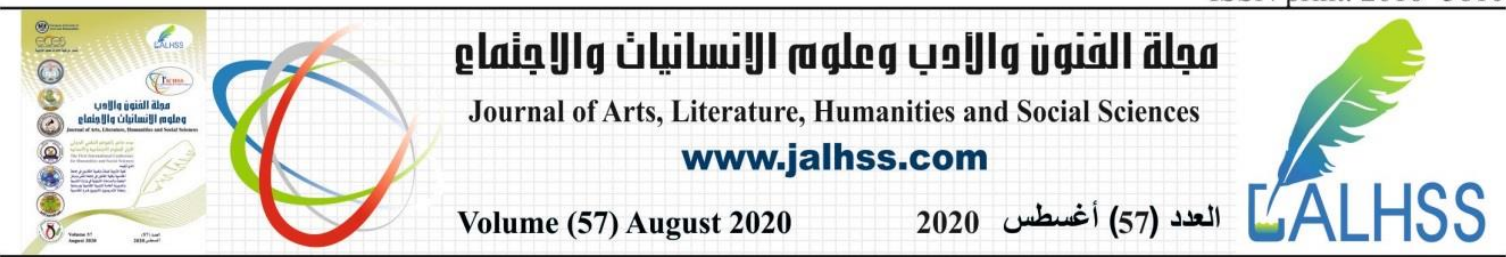

، ، 1990، ص479 ) ، في حين عرفها رأي آخر بأنها " فترة زمنية بين لحظتين يحددها القانون ويقيد بها

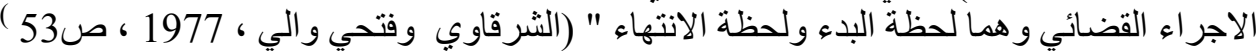

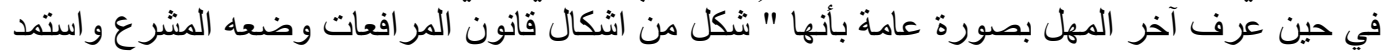

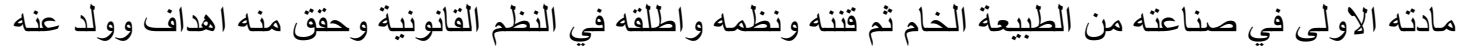

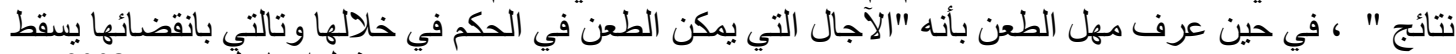

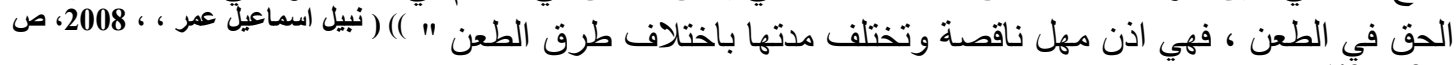

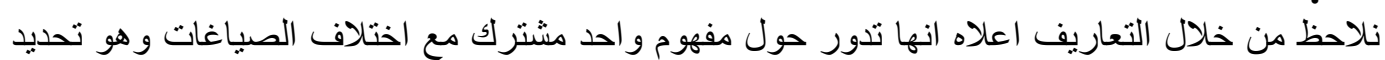

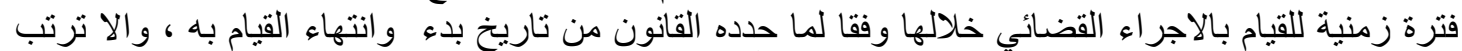

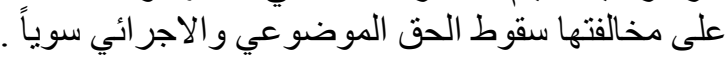

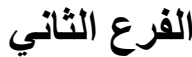

\section{باءع سريان مدد الطعن}

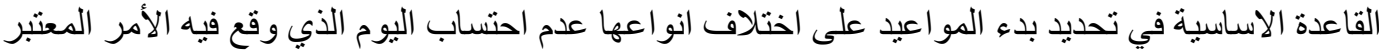

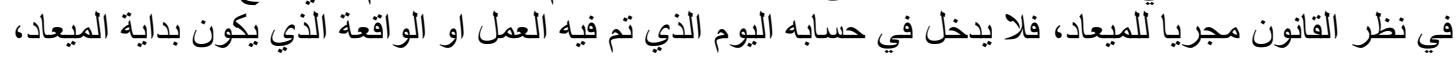

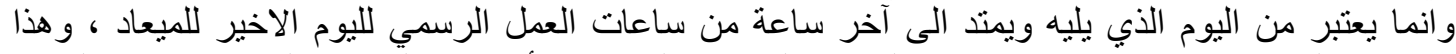

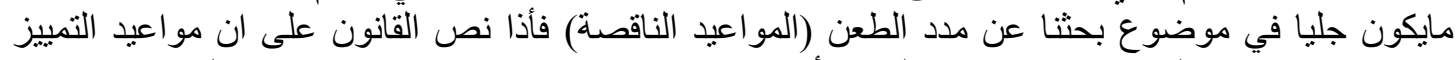

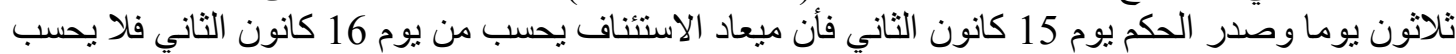

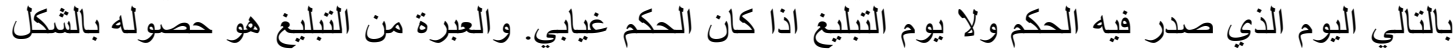

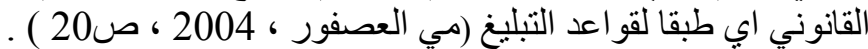
وفي حال تعدد الخصوم المككن توجيه الطعن اليهم ، فأن تبليغ الحكم الحاصل لاحدهم يجعل مهلة الطعن

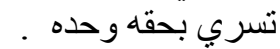

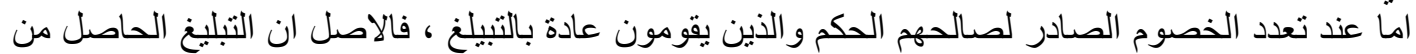

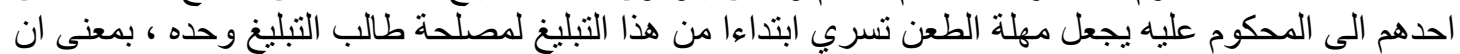

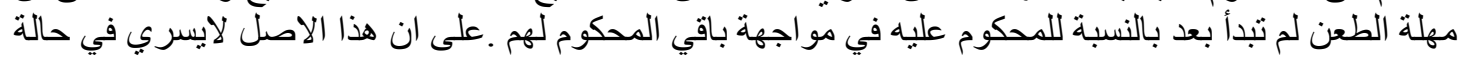

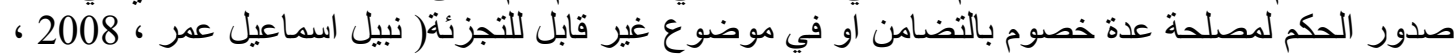

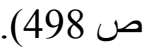
و هذا مانص عليه المشرع العر اقي في قانون المرافعات المدنية العراقي بأن مهلة الطعن تبدأ من تاريخ تبليغ

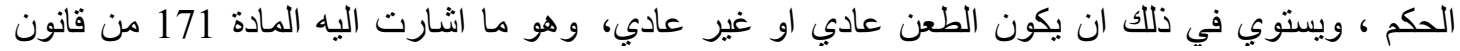

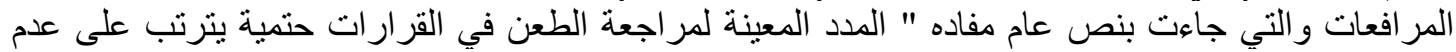

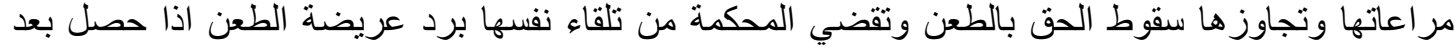
انقضاء المدد القانو نية ".

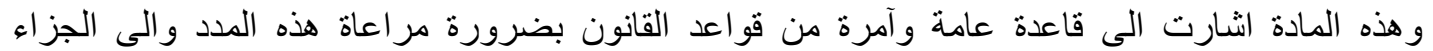

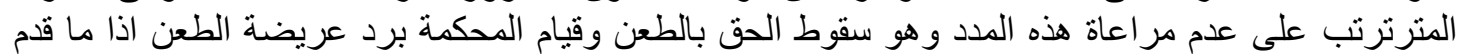

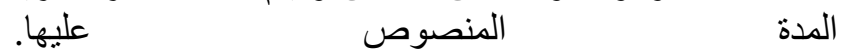

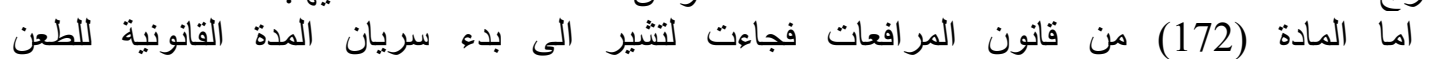

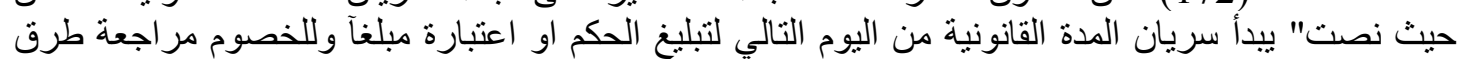

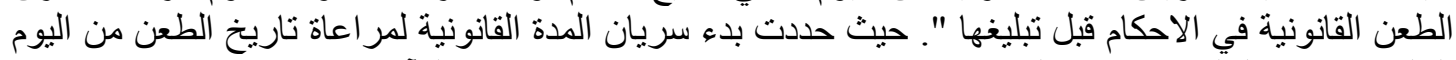

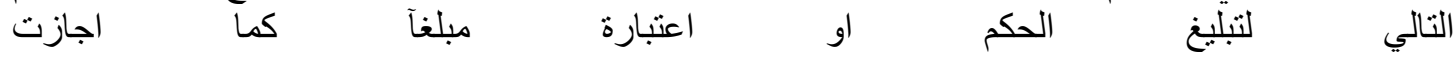
للخصوم مر اجعة طرق الطعن قبل تبليغها. 


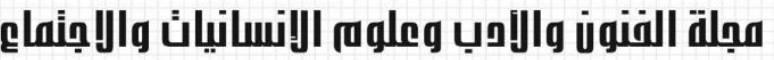

Journal of Arts, Literature, Humanities and Social Sciences

\section{www.jalhss.com}

\section{الفرع الثالث

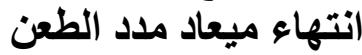

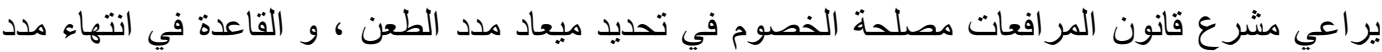

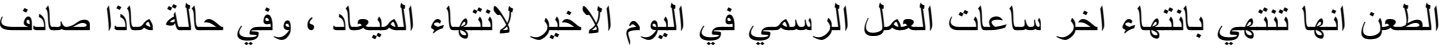

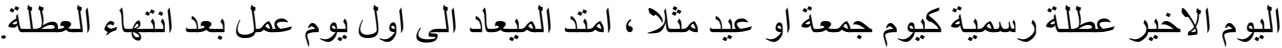

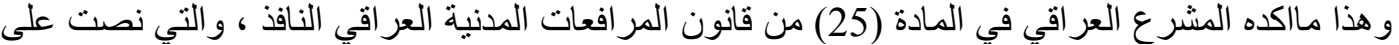

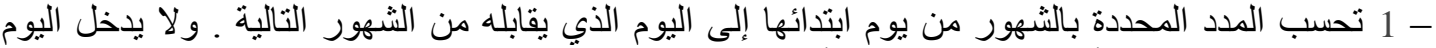

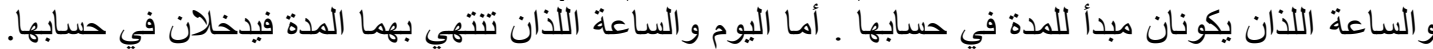

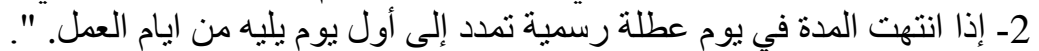

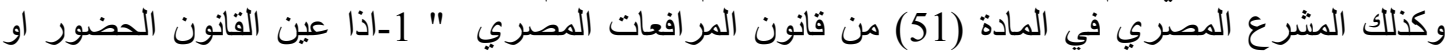

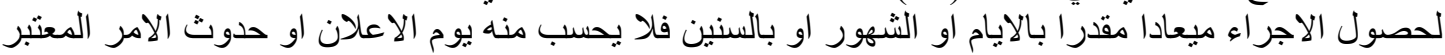

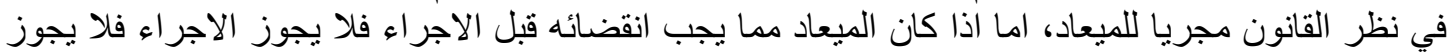

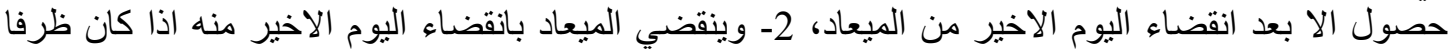

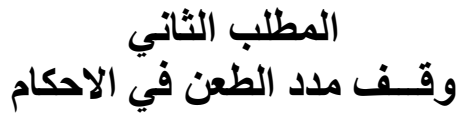

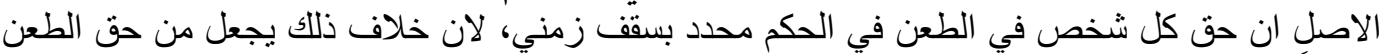

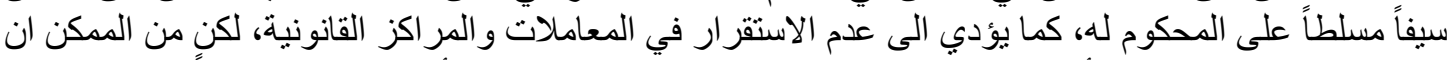

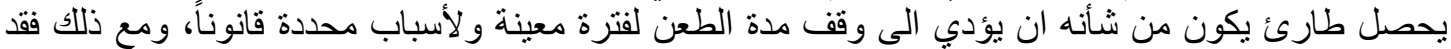

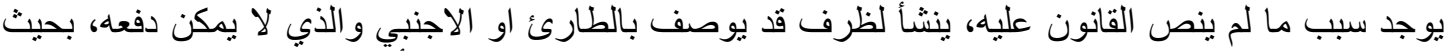

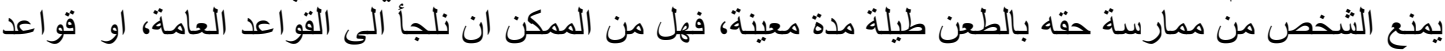

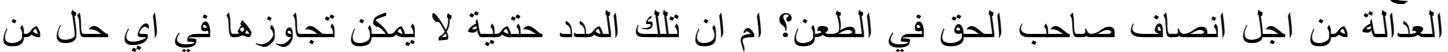

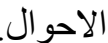

لذا سنقسم هذا المطلب على فرعين، نبين في الفرع الاول الوضن الوضع في ظل قانون المر افعات المدنية ، في حين نخصص الفرع الثاني الى الوضع خارج قانون الَّر افعات المدنية.

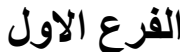

\section{الوضع في ظل قانون المرافعات الماون المدنية}

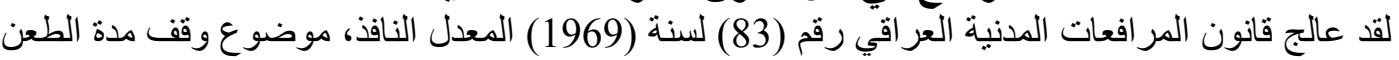

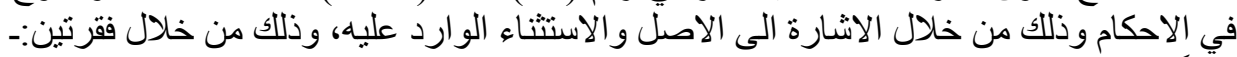

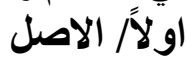

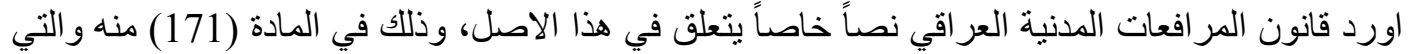

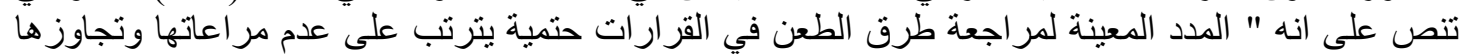

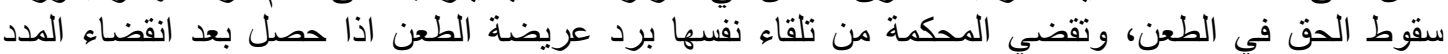

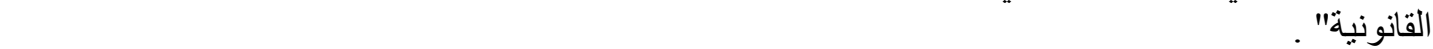

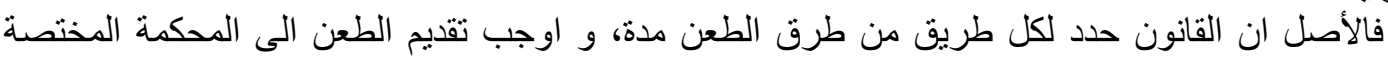

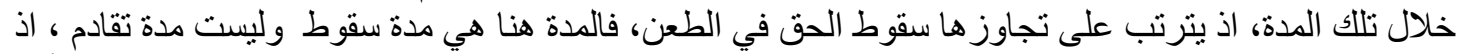

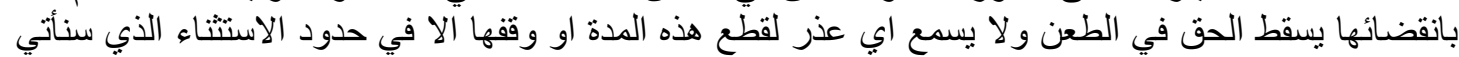

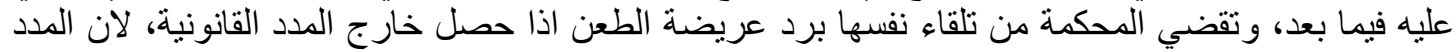

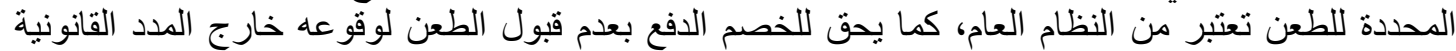

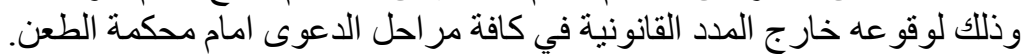

وان هدف القانون من جعل مدد الطعن حتمية واعتبار ها من النظام العام هو تأمين استقر ار المر اكز القانونية

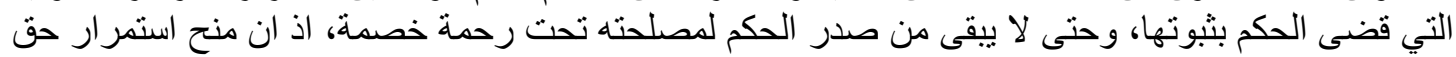




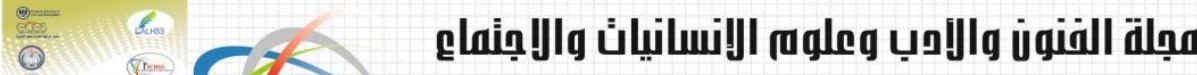 \\ Journal of Arts, Literature, Humanities and Social Sciences www.jalhss.com

الطعن الى ما لا نهاية يجعله سيفاً مسلطاً على المحكوم له، ويؤدي الى تراكم القضايا امام المحكمة وتأخير

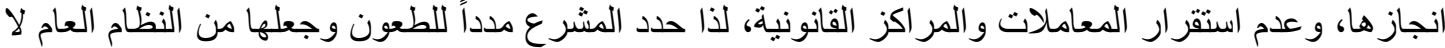

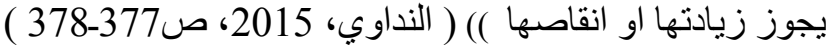

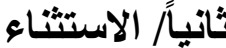

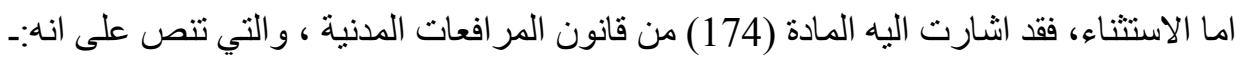

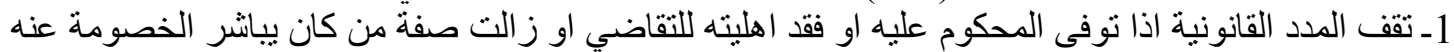

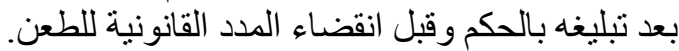
2ـ لا يزول وقف المدة الا بعد تبليغ الحكم الى الورثنة او احدهم في اخر موطن كان للمورث، او موطن من يقوم

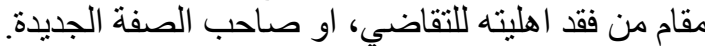

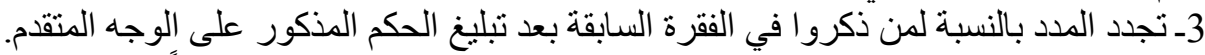

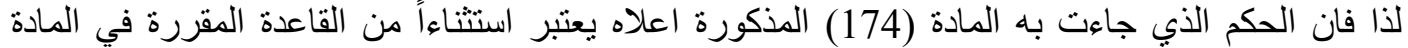

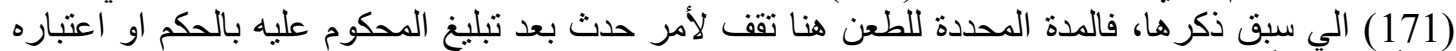

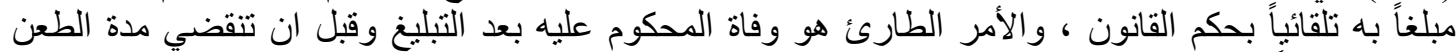

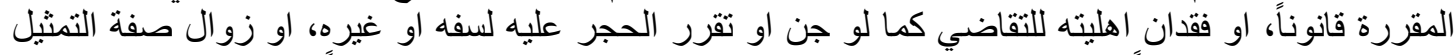

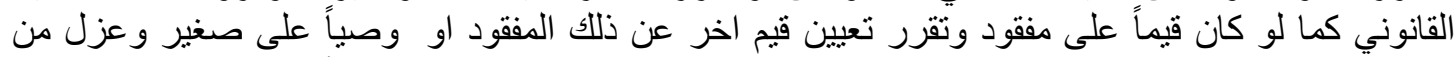

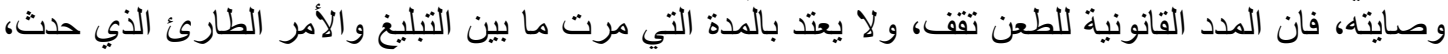

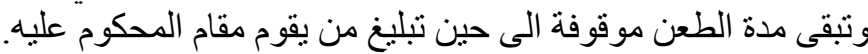

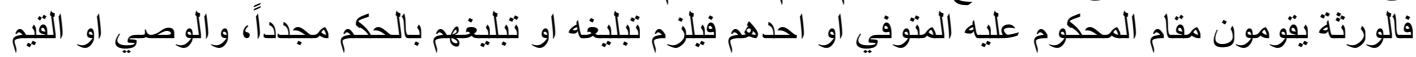

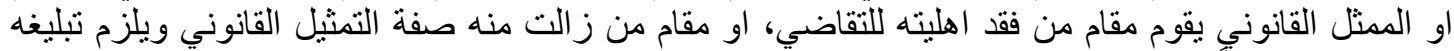

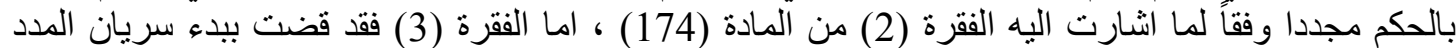

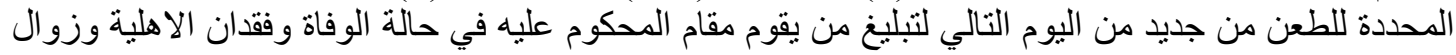

و هذا الحكم تقتضيه العدالة، اذ يتاح لمن يقوم مقام المحكوم عليه مراجعة طرق الطعن القانونية بالحكم

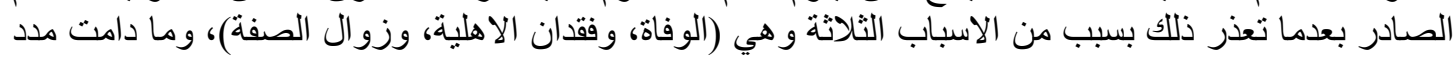

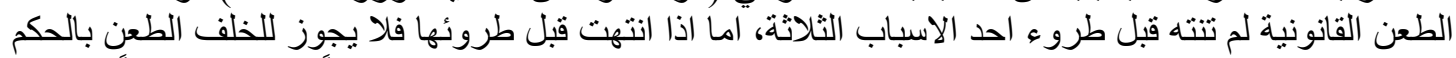

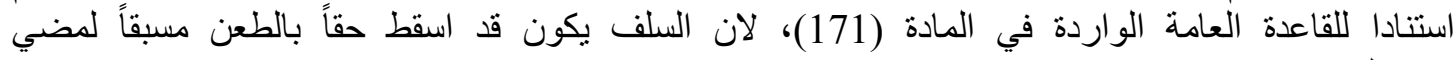

\section{الوضع خارج اطار قانون الثر افعات الثرات المدنية}

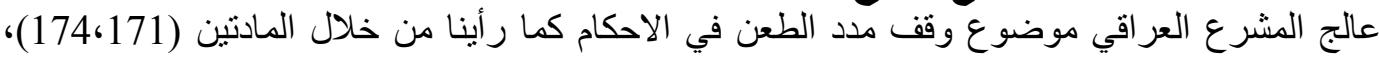

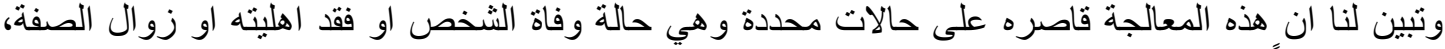

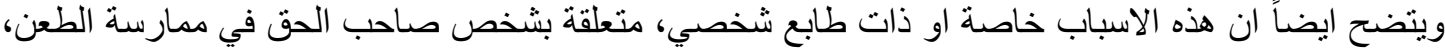

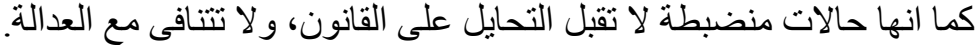

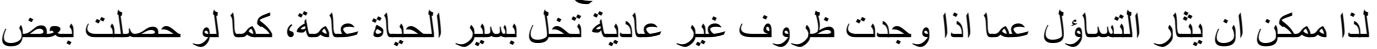

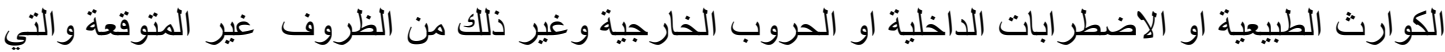

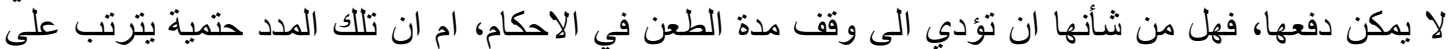

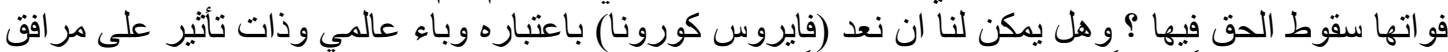

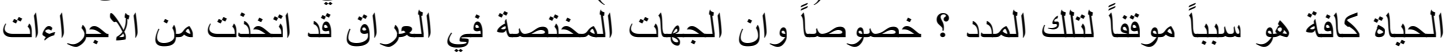

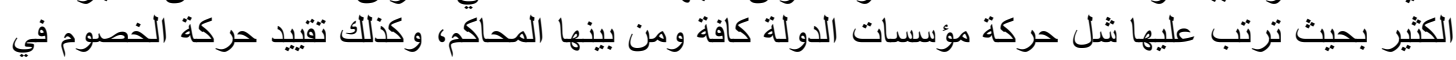
التنقل وممارسة حقهم في مر اجعة المحاكم المختصنة.

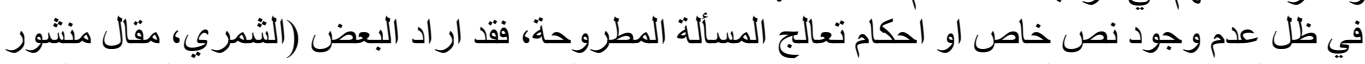

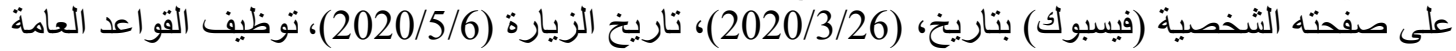

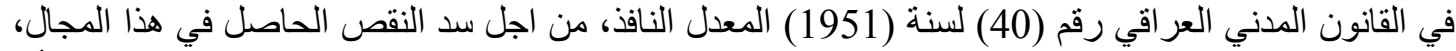
من خلال اعتبار ان ما يتخذ من اجر اءات في ظل انتشار فايروس كورونا ظرف طان طارئ غير منوقع من شأنه 


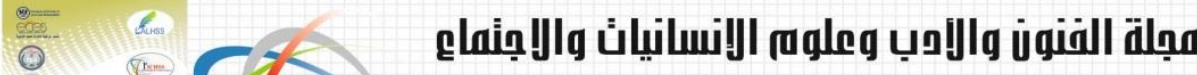 \\ Journal of Arts, Literature, Humanities and Social Sciences www.jalhss.com

خلق استحالة نسبية، وبالتالي قوة قاهرة تمثل مانع حقيقي يستحيل معه على المدعي ان يطالب بحقه، حيث نصت

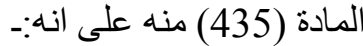

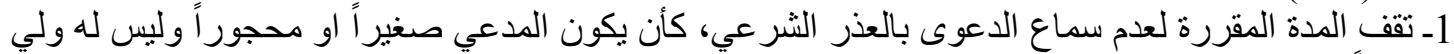

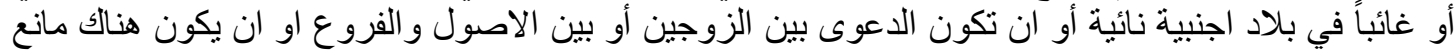

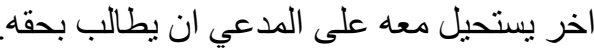

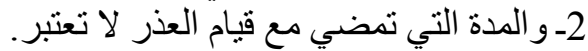

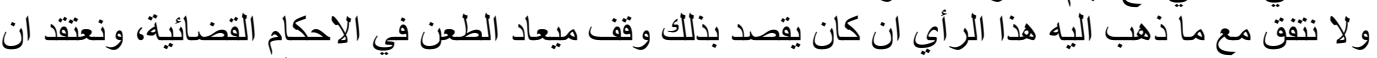

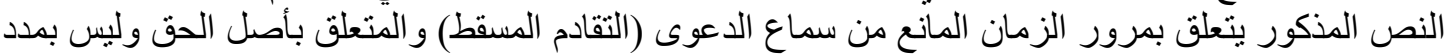

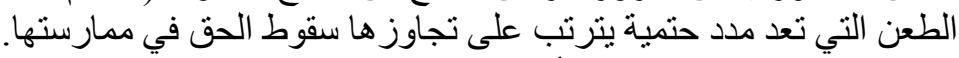

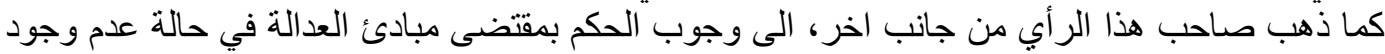

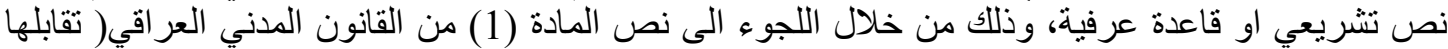

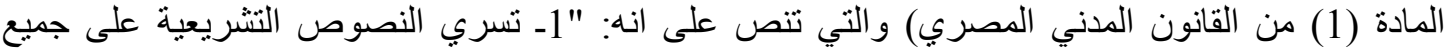

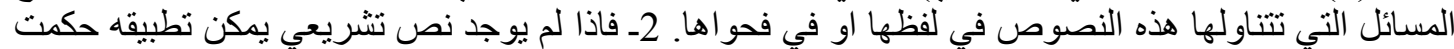

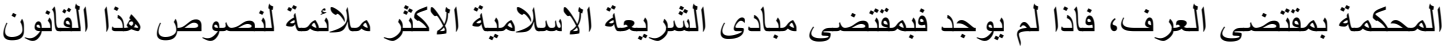

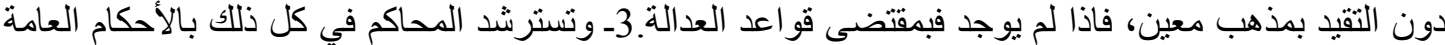

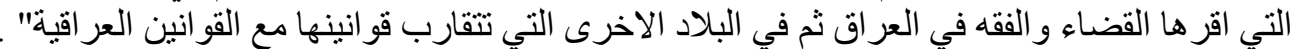

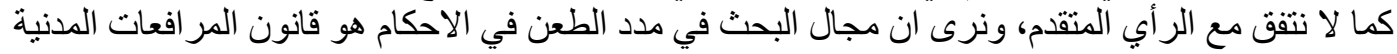

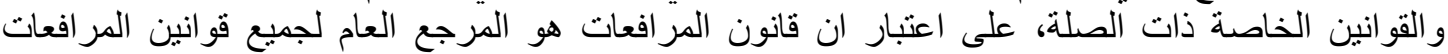

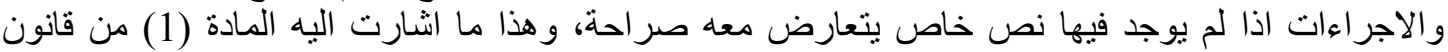

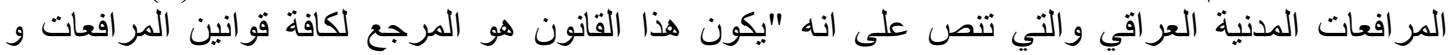

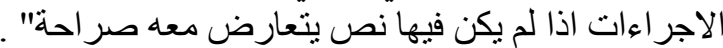

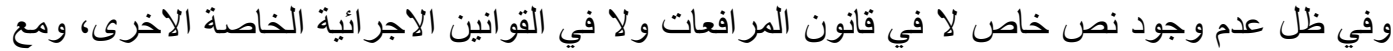

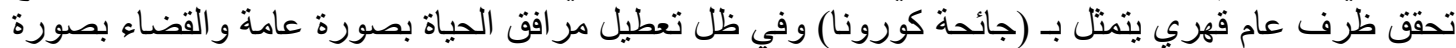

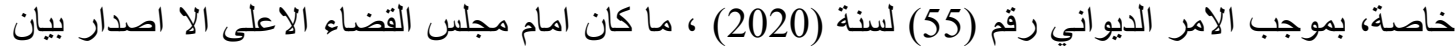

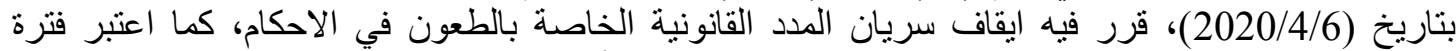

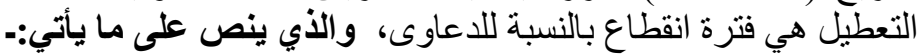

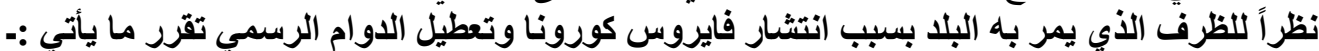

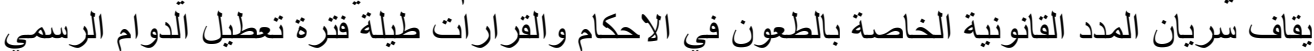

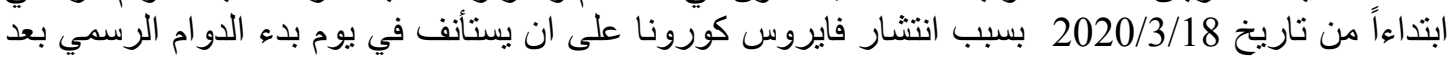
تعتبر فترة تعطيل الدوام الرسمي فترة انقطاع للمر افعة لكافة الدعاوى لحين زوال السبب(بيان مجلس

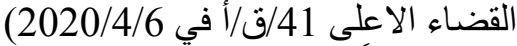

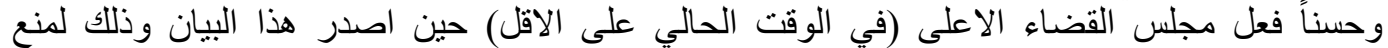

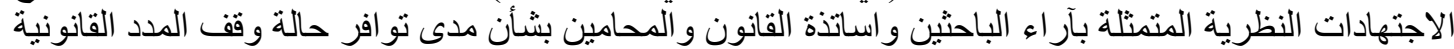

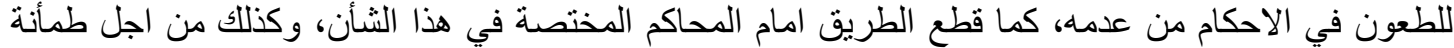
الخصوم في المحافظة على حقوقهم.

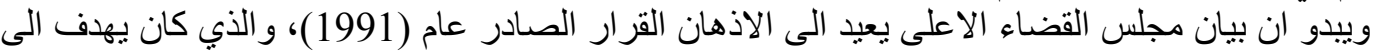

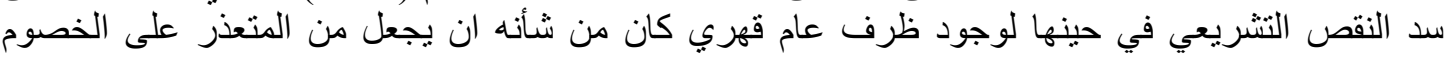

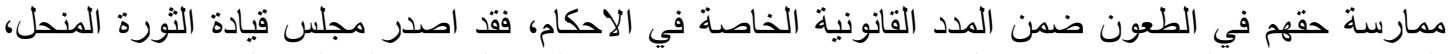

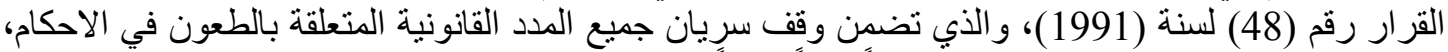

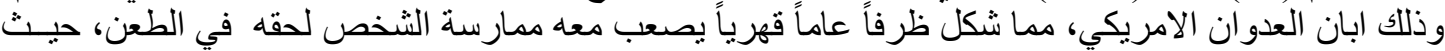

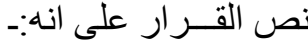

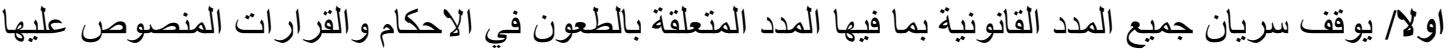
في قانون المر افعات المدنية رقم (83) لسنة (1969) المعدل، وقانون اصول المحاكية فيات المات الجزائية رقم (23) 


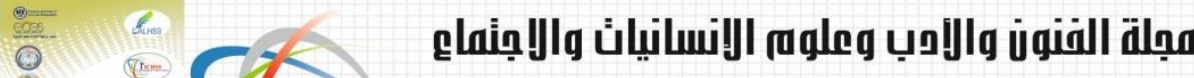 \\ Journal of Arts, Literature, Humanities and Social Sciences \\ www.jalhss.com

لسنة (1971) المعدل، او في اي قانون او نص اخر، اعتبار أ من تاريخ بدء العدوان الامريكي الصهيوني على

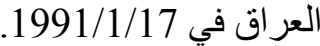

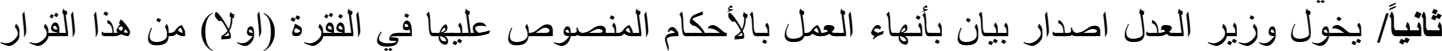

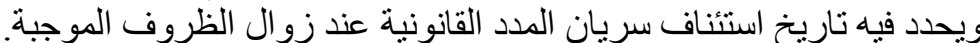

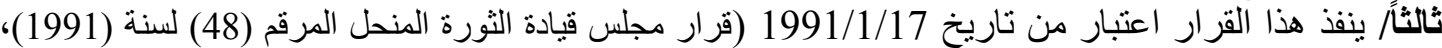

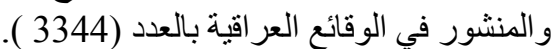

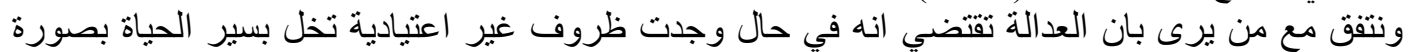

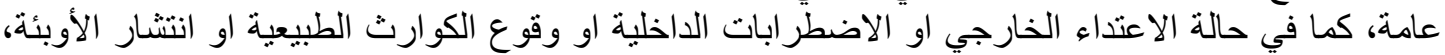

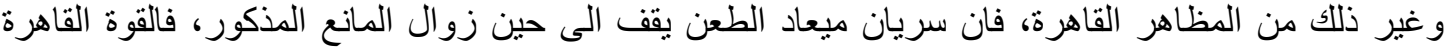

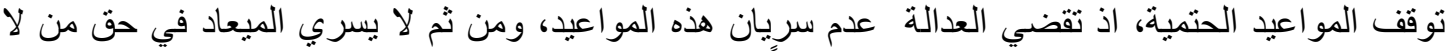

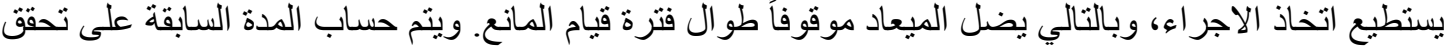
سبب الوقف ويضاف اليها المدة اللاحقة على زواله بما يؤدي الى استكمال الميعاد الذي يتطلبه القانون(الهندي،

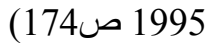

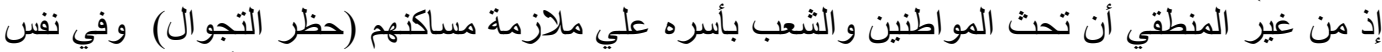

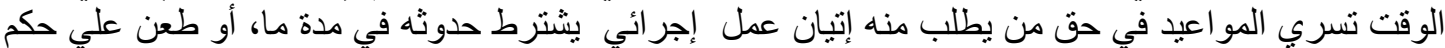

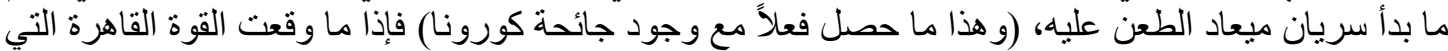

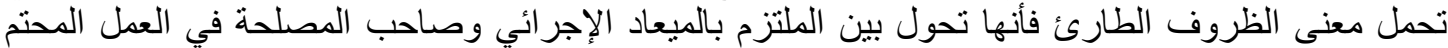

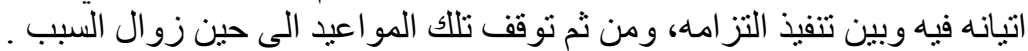

وتطبيقاً لذلك فقد قضت محكمة النقض المصرية في الطعن رقم (12079) لسنة (81) قضائية جلسة

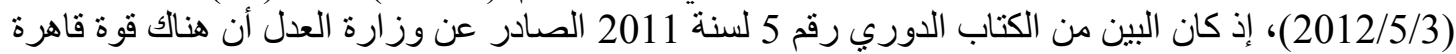

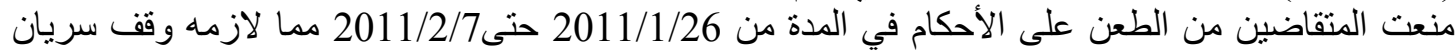

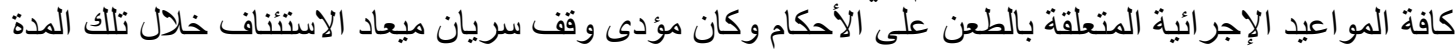

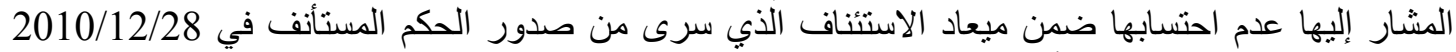

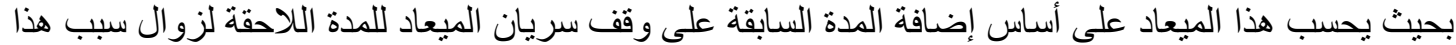

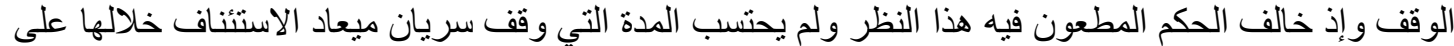
ما سلف بيانه فإنه يكون قد أخطأ في تطبيق القانون وشابه الندابه القصور في التسبيب .

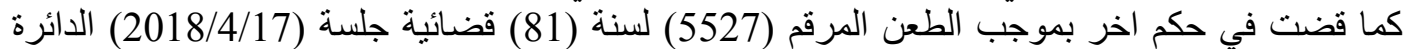

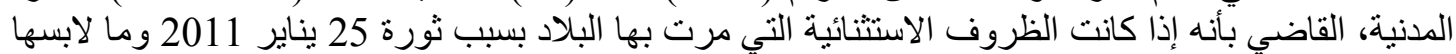

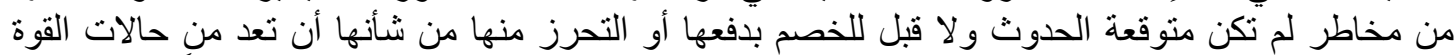

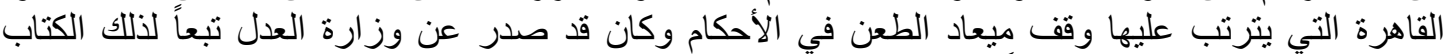

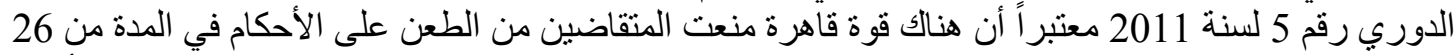

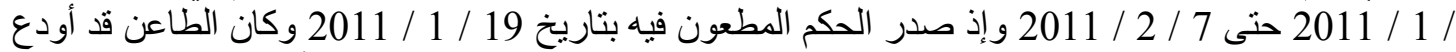

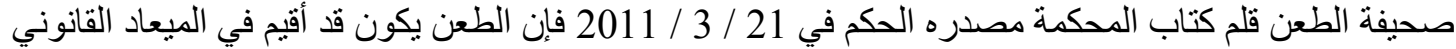

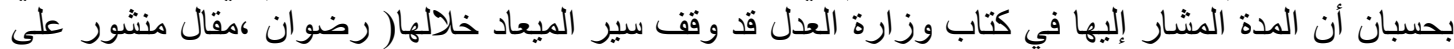

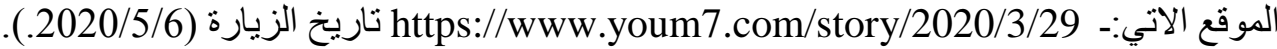

الخاتمة

في نهاية بحثنا في " أثر فايروس كورونا على مدد الطعن بالاحكام القضائية " يمكننا ان ندرج مجمو عة من البنات النتائج و التوصيات التي نأمل ان تكون فايرون مساهمة في ميدان البحث العلمي وهي :اولاًا النتائج 1- تعد مدد الطعن حتمية يترتب على عدم مر اعاة مو اعيدها سقوط الحق فيها كونها من النظام العام. 


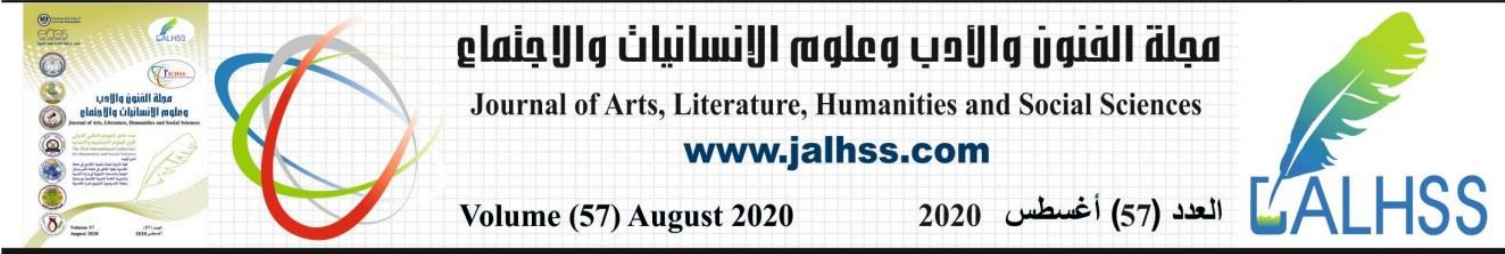

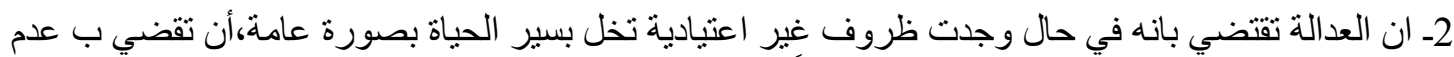

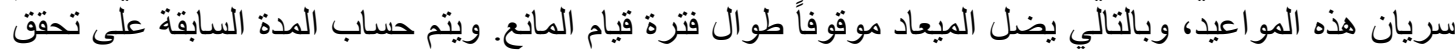

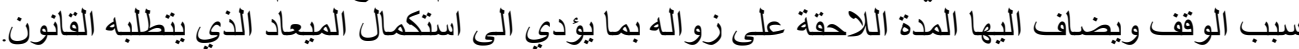
ثنانيا/ التوصيات نوصي بما يلي :- الميات

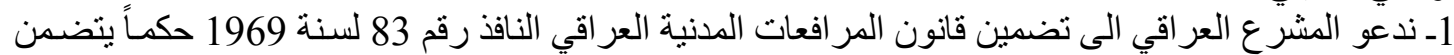

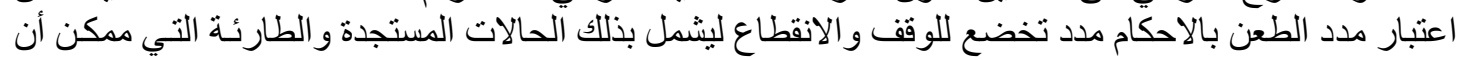

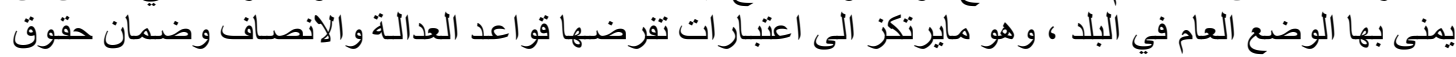

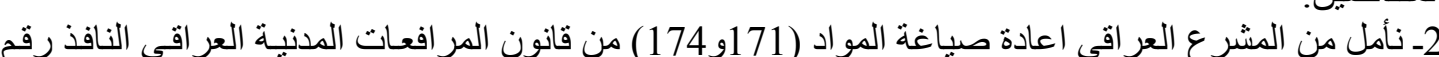

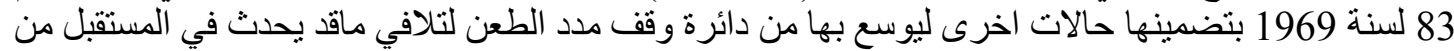

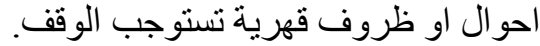
3- ولعدم تأثير جائحة كورونا علير على سريان مدد الطعن بالأحكام نقتر ح على المحاكم باعتمـاد تقديم طلبات الطعن الكترونيا لحين تغطية الامر تشريعيا . الكائ

\section{(المصادر

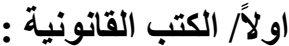

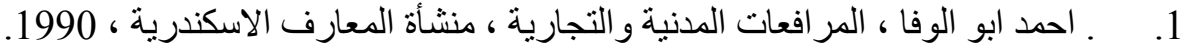

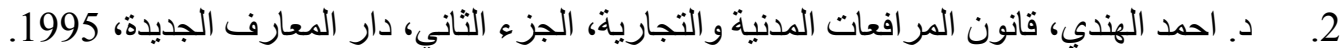

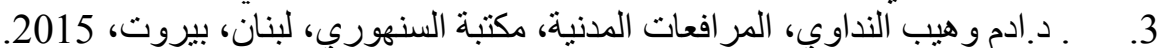

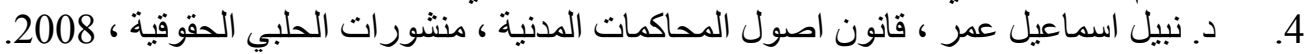

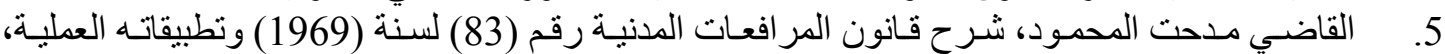

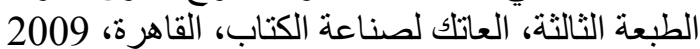

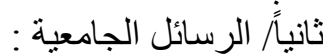

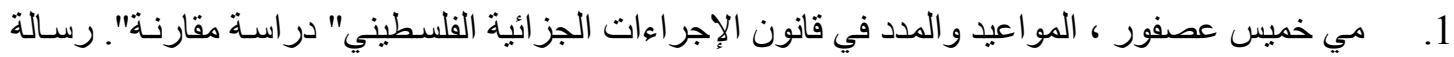

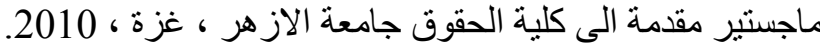

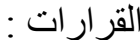

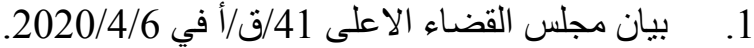

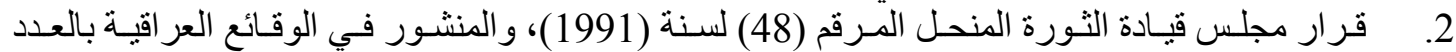

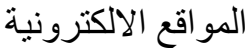
1.

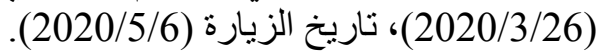

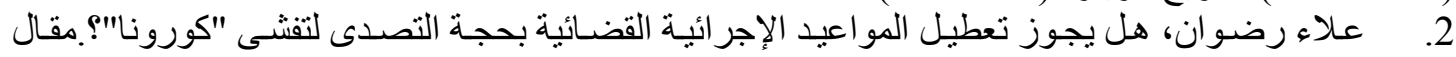
منشور على الموقع الاتي:- https:/www.youm7.com/story/2020/3/29 ناريخ الزيارة (2020/5/6.). 


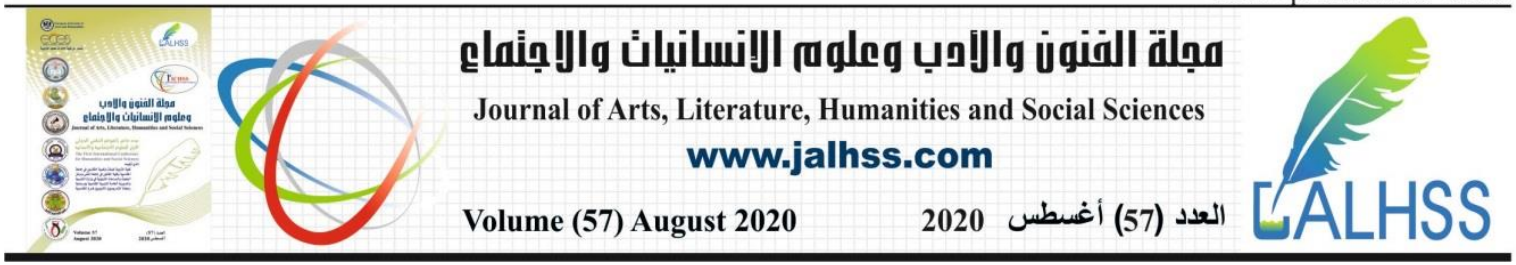

References

First / law books -

1.-Ahmad Abu Al-Wafa, Civil and Commercial Procedures, Al-Maaref Establishment, Alexandria, 1990.

.2-Dr. Ahmed Al-Hindi, Civil and Commercial Procedures Law, Part Two, New Knowledge House, 1995.

..3-Dr. Adam Wahib Al-Nadawi, Civil Procedure, Al-Sinhouri Library, Lebanon, Beirut, 2015.

4-Dr. Nabil Ismail Omar, Civil Procedure Law, Al-Halabi Human Rights Publications, 2008.

.5-Judge Medhat Al-Mahmoud, Explanation of the Civil Procedure Law No. (83) for the year (1969) and its practical applications, third edition, Al Atak for the book industry, Cairo, 2009.

\section{Second / university theses:}

.1-Mai Khamis Asfour, The Appointments and Durations in the Palestinian Criminal Procedure Law "A Comparative Study". Master Thesis submitted to the Faculty of Law, Al-Azhar University, Gaza, 2010.

\section{Decisions:}

.1-Statement of the Supreme Judicial Council 41 / Q / A on 6/4/2020.

.2-Resolution of the dissolved Revolutionary Command Council No. (48) for the year (1991), published in the Iraqi incidents, number (3344).

\section{Websites}

.1-Legal Adviser, Jassim Al-Shammari, an article published on his personal page (Facebook) on (3/26/2020), the date of the visit (6/5/2020.(

.2-Alaa Radwan, is it permissible to suspend the judicial procedural appointments, on the pretext of dealing with the "Corona" outbreak? 2020.). 